\title{
Molecular probes and switches for functional analysis of receptors, ion channels and synaptic networks
}

\author{
Pau Gorostiza ${ }^{1 *}$, Daniele Arosio ${ }^{2 *}$ and Piotr Bregestovski ${ }^{3 *}$ \\ 1 ICREA and Institute for Bioengineering of Catalonia, Barcelona, Spain \\ 2 Institute of Biophysics, National Research Council and FBK, Trento, Italy \\ ${ }^{3}$ Inserm UMR1106, Brain Dynamics Institute, University Aix-Marseille, Marseille, France \\ *Correspondence: pau@icrea.cat; daniele.arosio@cnr.it; piotr.bregestovski@univ-amu.fr \\ Edited by: \\ Jochen C Meier, Max Delbrück Center for Molecular Medicine, Germany
}

Keywords: biosensors, chloride imaging, pH monitoring, optogenetics, optopharmacology, photochromic ligands

Photochromic switches and genetically encoded biosensors have become powerful tools for monitoring and modulating the activity of neurons and neuronal networks. Our understanding of the mechanisms underlying the development and functioning of the nervous system has greatly advanced in recent years thanks to advancements in these effective molecular and genetic tools. The idea of this Special Research Issue of Frontiers in Molecular Neuroscience is to provide an overview of the approaches in this area of research, and to present new applications in molecular imaging of ions and remote activation of receptors, ionic channels and synaptic networks. The issue contains experimental and methodological papers as well as review articles dealing with molecular tools for investigation and modulation of neuronal function. It can be divided into two main sections: (i) genetically encoded probes for non-invasive monitoring of ions and ATP; and (ii) optogenetic and optopharmacologic tools for control of neuronal activity with light.

In the first section, several papers are devoted to the use of probes for the non-invasive monitoring of intracellular chloride $\left(\left[\mathrm{Cl}^{-}\right]_{\mathrm{i}}\right)$. A sensor with improved sensitivity to chloride, called Cl-Sensor (Markova et al., 2008), has previously been used to measure $\left[\mathrm{Cl}^{-}\right]_{\mathrm{i}}$ in different cell types and to analyse the function of the potassium-chloride transporter KCC2 in hippocampal neurons (Bregestovski et al., 2009; Waseem et al., 2010; Pellegrino et al., 2011). In this issue, improved methods for the stable, longlasting ratiometric recording of $\left[\mathrm{Cl}^{-}\right]_{i}$ are described, and these provide a technique for monitoring $\mathrm{Cl}$-Sensor fluorescence in different cell types using conventional fluorescence microscopy set-ups (Friedel et al., 2013). Cl-Sensor has also been used to analyse the mechanisms leading to changes in neuronal $\left[\mathrm{Cl}^{-}\right]_{\mathrm{i}}$ during glioma invasion (Bertollini et al., 2012). The authors demonstrated that glioma cells induce release of amino acids, which may dynamically alter $\mathrm{Cl}^{-}$equilibrium in surrounding neurons. This causes interference with their inhibitory balance, probably leading to physiological and pathological consequences (Bertollini et al., 2012). An important development is the production of two mouse lines expressing $\mathrm{Cl}$-Sensor, which allows ratiometric monitoring of $\left[\mathrm{Cl}^{-}\right]_{\mathrm{i}}$ in specific cell types in vivo (Batti et al., 2013).

Recently, a probe allowing simultaneous monitoring of $\mathrm{Cl}^{-}$ and $\mathrm{H}^{+}$has been developed (Arosio et al., 2010). In this issue, a study reports the intracellular calibration and functional characterization of this sensor, called ClopHensor, and its two derivatives: the membrane-targeting PalmPalm-ClopHensor and the H148G/V224L mutant with improved $\mathrm{Cl}^{-}$affinity and reduced $\mathrm{pH}$ dependence (Mukhtarov et al., 2013). This study identified the different ClopHensor variants as promising tools for non-invasive measurement of $\left[\mathrm{Cl}^{-}\right]_{\mathrm{i}}$ and $\mathrm{pH}$ in living cells. The usefulness of GFP-derived $\mathrm{pH}$ reporters to quantify intracellular $\mathrm{pH}$ in the context of changing neuronal activity is demonstrated in another study, where the authors compare three genetically encoded probes to analyse $\mathrm{pH}$ transients evoked by epileptiform activity in two separate in vitro models of temporal lobe epilepsy (Raimondo et al., 2012).

Two papers illustrate the use of genetically encoded probes to analyse physiologically important ions or molecules in different cellular compartments (Surin et al., 2012; Akerboom et al., 2013). The first study describes a family of genetically encoded calcium indicators. This engineered set of chromatic variants facilitates experiments in functional imaging and optogenetics and allows the simultaneous monitoring of intracellular calcium $\left(\left[\mathrm{Ca}^{2+}\right]_{\mathrm{i}}\right)$ in different cell types (i.e., neurons and astrocytes) or cellular compartments (i.e., cytoplasm and mitochondria) (Akerboom et al., 2013). The second contribution presents a comparative analysis of cytosolic and mitochondrial ATP synthesis in embryonic and postnatal hippocampal neuronal cultures (Surin et al., 2012). The authors simultaneously monitored ATP and mitochondrial membrane potential using a genetically encoded sensor (Imamura et al., 2009). Their observations suggest that ATP synthesis is predominantly glycolytic in embryonic but not in postnatal neuronal cultures.

The last article in the first section (Brondi et al., 2012) describes a method for combining calcium imaging and genetic labeling of specific cell types in the mouse brain, using fluorophores with very similar emission spectra. The authors exploit the differences in two-photon emission spectra of the dyes and demonstrate that this technique can be extended to other fluorophores.

The second section of this Special Research Issue presents optogenetic tools and photoswitches for the optical control of neuronal activity. A method for studying neuronal plasticity following long-term neuronal stimulation using Channelrhodopsin2 and monitoring by multi-electrode arrays is presented by Lignani et al. (2013). Optogenetics can also be used to study the molecular mechanisms associated with drugs of abuse (Chandra et al., 2013). The authors show that altering the activity in specific 
neural circuits can result in the regulation of cocaine-induced actin-cytoskeleton dynamics and behavioral plasticity.

The fields of optopharmacology and optochemical genetics are reviewed by Sandoz and Levitz (2013) and Mourot et al. (2013) with special emphasis on their application to neuronal potassium channels. Ion channels and receptors can be photosensitized using synthetic light-regulated ligands that either diffuse freely or are permanently conjugated to their target channel. Light acting on the ligands allows their reversible binding to ion channels, leading to activation or inhibition depending on the nature of the ligand. These methods provide powerful biophysical tools for fundamental studies of ion channels, and promising therapeutic applications such as the photosensitization of blind retinas. The study by Izquierdo-Serra et al. (2013) applies calcium photocurrents through a light-gated glutamate receptor to control calcium-regulated exocytosis and optically modulate neurotransmission.

The issue concludes with two articles that are focused on the approaches and techniques to analyse Cl-selective receptoroperated channels. Lynagh and Lynch (2012) used a voltageclamp fluorometry to quantitatively monitor agonist-induced conformational and fluorescence changes at locations distant from the ionic pore. In this way, they analyzed the molecular mechanisms of cys-loop channel modulation by ivermectin. The review by Schaefer et al. (2012) describes mouse models in combination with modern imaging techniques as excellent tools for bridging the gap between adaptation and remodeling of inhibitory synapses under physiological and pathological conditions.

We are grateful to all authors and reviewers for their efforts in providing an excellent overview of these rapidly expanding fields.

\section{REFERENCES}

Akerboom, J., Carreras Calderón, N., Tian, L., Wabnig, S., Prigge, M., Tolö, J., et al., (2013). Genetically encoded calcium indicators for multi-color neural activity imaging and combination with optogenetics. Front. Mol. Neurosci. 6:2. doi: 10.3389/fnmol.2013.00002

Arosio, D., Ricci, F., Marchetti, L., Gualdani, R., Albertazzi, L., and Beltram, F. (2010). Simultaneous intracellular chloride and $\mathrm{pH}$ measurements using a GFP-based sensor. Nat. Methods 7, 516-518. doi: 10.1038/nmeth.1471

Batti, L., Mukhtarov, M., Audero, E., Ivanov, A., Paolicelli, O., Zurborg, S., et al. (2013). Transgenic mouse lines for non-invasive ratiometric monitoring of intracellular chloride. Front. Mol. Neurosci. 6:11. doi: 10.3389/fnmol.2013. 00011

Bertollini, C., Murana, E., Mosca, L., D’Erme, M., Scala, F., Francioso, A., et al. (2012). Transient increase in neuronal chloride concentration by neuroactive aminoacids released from glioma cells. Front. Mol. Neurosci. 5:100. doi: 10.3389/fnmol.2012.00100

Bregestovski, P., Waseem, T., and Mukhtarov, M. (2009). Genetically encoded optical sensors for monitoring of intracellular chloride and chlorideselective channel activity. Front. Mol. Neurosci. 2:15. doi: 10.3389/neuro.02. 015.2009

Brondi, M., Sato, S. S., Rossi, L. F., Ferrara, S., and Ratto, G. M. (2012). Finding a needle in a haystack: identification of EGFP tagged neurons during calcium imaging by means of two-photon spectral separation. Front. Mol. Neurosci. 5:96. doi: $10.3389 /$ fnmol.2012.00096
Chandra, R., Lenz, J. D., Gancarz, A. M., Chaudhury, D., Schroeder, G. L., Han, M.H., et al. (2013). Optogenetic inhibition of D1R containing nucleus accumbens neurons alters cocaine-mediated regulation of Tiam1. Front. Mol. Neurosci. 6:13. doi: $10.3389 /$ fnmol.2013.00013

Friedel, P., Bregestovski, P., and Medina, I. (2013). Improved method for efficient imaging of intracellular $\mathrm{Cl}(-)$ with $\mathrm{Cl}$-Sensor using conventional fluorescence setup. Front. Mol. Neurosci. 6:7. doi: 10.3389/fnmol.2013.00007

Imamura, H., Huynh, K. P., Togawa, H., Saito, K., Iino, R., and Kato-Yamada, Y. (2009). Visualization of ATP levels inside single living cells with fluorescence resonance energy transfer-based. Proc. Natl. Acad. Sci. U.S.A. 106, 15651-15656. doi: 10.1073/pnas.0904764106

Izquierdo-Serra, M., Trauner, D., Llobet, A., and Gorostiza, P. (2013). Optical modulation of neurotransmission using calcium photocurrents through the ion channel LiGluR. Front. Mol. Neurosci. 6:3. doi: 10.3389/fnmol.2013.00003

Lignani, G., Ferrea, E., Difato, F., Amarù, J., Ferroni, E., Lugarà, E., et al. (2013). Long-term optical stimulation of channelrhodopsin-expressing neurons to study network plasticity. Front. Mol. Neurosci. 6:22. doi: $10.3389 /$ fnmol.2013.00022

Lynagh, T., and Lynch, J. W. (2012). Molecular mechanisms of Cys-loop ion channel receptor modulation by ivermectin. Front. Mol. Neurosci. 5:60. doi: 10.3389/fnmol.2012.00060

Markova, O., Mukhtarov, M., Real, E., Jacob, Y., and Bregestovski, P. (2008). Genetically encoded chloride indicator with improved sensitivity. J. Neurosci. Methods 170, 67-76. doi: 10.1016/j.jneumeth.2007.12.016

Mourot, A., Tochitsky, I., and Kramer, R. H. (2013). Light at the end of the channel: optical manipulation of intrinsic neuronal excitability with chemical photoswitches. Front. Mol. Neurosci. 6:5. doi: 10.3389/fnmol.2013.00005

Mukhtarov, M., Liguori, L., Waseem, T., Rocca, F., Buldakova, S., Arosio, D., et al. (2013). Calibration and functional analysis of three genetically encoded $\mathrm{Cl}(-) / \mathrm{pH}$ sensors. Front. Mol. Neurosci. 6:9. doi: 10.3389/fnmol.2013.00009

Pellegrino, C., Gubkina, O., Schaefer, M., Becq, H., Ludwig, A., Mukhtarov, M., et al. (2011). Knocking down of the KCC2 in rat hippocampal neurons increases intracellular chloride concentration and compromises neuronal survival. J. Physiol. 589, 2475-96. doi: 10.1113/jphysiol.2010.203703

Raimondo, J. V., Irkle, A., Wefelmeyer, W., Newey, S. E., and Akerman, C. J. (2012). Genetically encoded proton sensors reveal activity-dependent $\mathrm{pH}$ changes in neurons. Front. Mol. Neurosci. 5:68. doi: 10.3389/fnmol.2012.00068

Sandoz, G., and Levitz, J. (2013). Optogenetic techniques for the study of native potassium channels. Front. Mol. Neurosci. 6:6. doi: 10.3389/fnmol.2013.00006

Schaefer, N., Vogel, N., and Villmann, C. (2012). Glycine receptor mutants of the mouse: what are possible routes of inhibitory compensation? Front. Mol. Neurosci. 5:98. doi: 10.3389/fnmol.2012.00098

Surin, A. M., Khiroug, S., Gorbacheva, L. R., Khodorov, B. I., Pinelis, V. G., and Khiroug, L. (2012). Comparative analysis of cytosolic and mitochondrial ATP synthesis in embryonic and postnatal hippocampal neuronal cultures. Front. Mol. Neurosci. 5:102. doi: 10.3389/fnmol.2012.00102

Waseem, T., Mukhtarov, M., Buldakova, S., Medina, I., and Bregestovski, P. (2010). Genetically encoded Cl-Sensor as a tool for monitoring of Cl-dependent processes in small neuronal compartments. J. Neurosci. Methods 193, 14-23. doi: 10.1016/j.jneumeth.2010.08.002

Received: 14 November 2013; accepted: 20 November 2013; published online: 13 December 2013.

Citation: Gorostiza P, Arosio D and Bregestovski P (2013) Molecular probes and switches for functional analysis of receptors, ion channels and synaptic networks. Front. Mol. Neurosci. 6:48. doi: 10.3389/fnmol.2013.00048

This article was submitted to the journal Frontiers in Molecular Neuroscience.

Copyright (c) 2013 Gorostiza, Arosio and Bregestovski. This is an open-access article distributed under the terms of the Creative Commons Attribution License (CC BY). The use, distribution or reproduction in other forums is permitted, provided the original author(s) or licensor are credited and that the original publication in this journal is cited, in accordance with accepted academic practice. No use, distribution or reproduction is permitted which does not comply with these terms. 